\title{
CAREERS
}

HOT COLLABORATOR Researcher reaches top rank as middle author $\mathbf{p . 4 4 7}$
REGULATIONS Study on scientific paperwork might cut red tape $\mathbf{p . 4 4 7}$
DATA-DRIVEN DECISIONS An academic uses

stats to choose a job blogs.nature.com/naturejobs

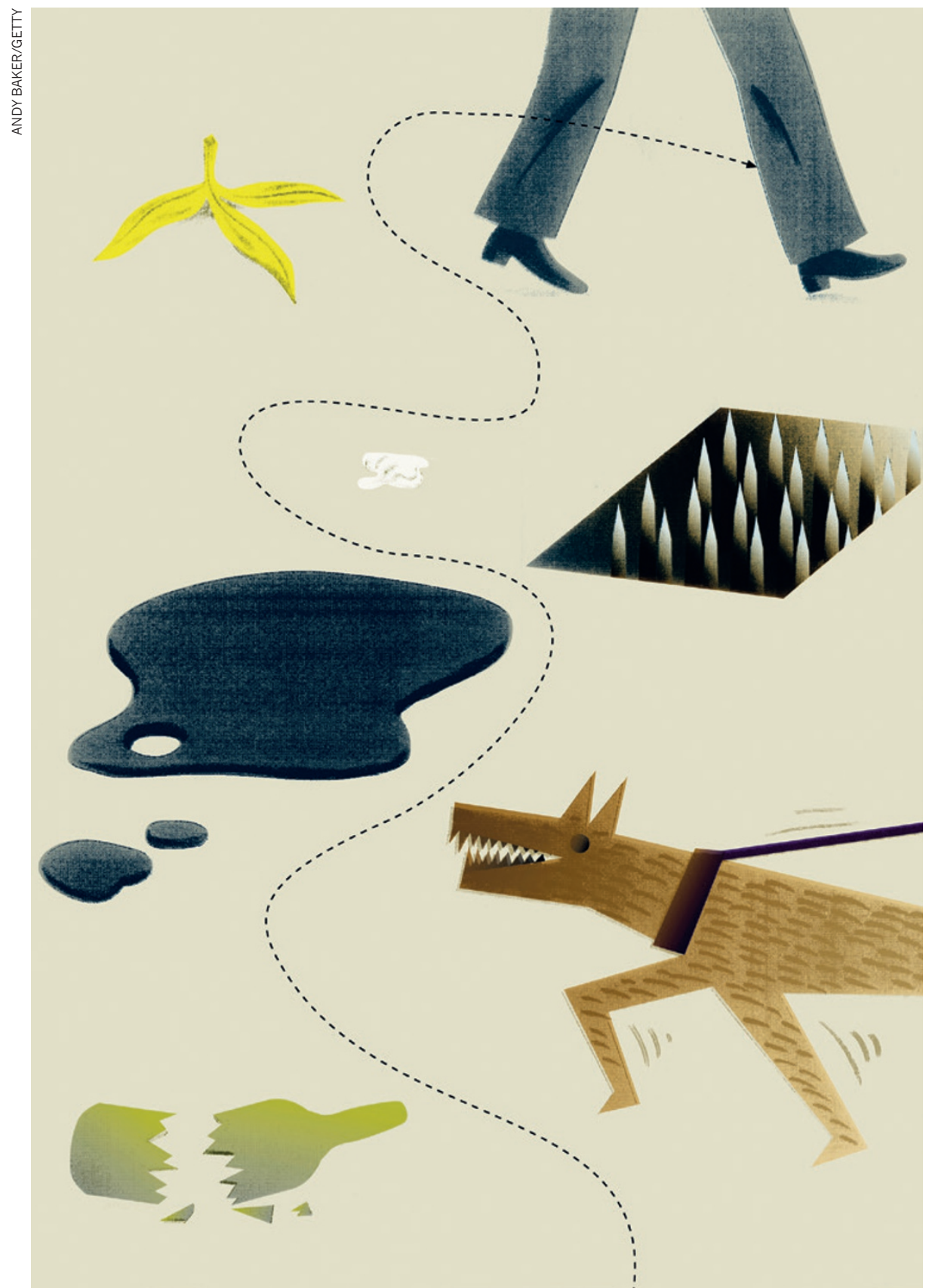

WORKPLACE SAFETY

Of all of the hazards faced by researchers, the biggest threat may be the human element.

BY CHRIS WOOLSTON

$\mathrm{B}$ efore each dig, archaeologist Michael Danti makes a mental inventory of everything that might go wrong. His work takes place in Syria and Kurdistan, so the list includes potential crises such as encountering poisonous scorpions, wild dogs, heat stroke, unexploded mines and, lately, armed secret police in search of insurgents. "Getting misidentified by the police is a big danger," he says. "Archaeologists and ISIS members can dress similarly. It's important for us to look as Western as possible."

Danti, who is employed by Boston University in Massachusetts, has heard his share of explosions and gunfire during his fieldwork, but nobody on his team has ever been seriously injured. Over the years, he has learned that staying safe often means watching out for the locals - wherever he may be. Before he focused on the Middle East, he conducted archaeology in the rural US Midwest. "That was just as dangerous," he says. "You could stumble across somebody's methamphetamine lab or get shot at by an angry farmer."

When most scientists think about safety, they focus on equipment, reagents or radiation - not armed militia or shotgun-wielding farmers. Violence of any sort is probably far down their list of concerns.

But no matter their area of study, scientists eventually encounter the human element, a potentially volatile hazard that does not come with operating instructions. From foreign soldiers or campus criminals to unhinged colleagues or team leaders with bad intentions harm can come from many directions. "It's like any other job," says Danti of his work. "The safety end of it is very important."

Whether at remote field camps or in the lab, scientists and institutions need to pay attention to personal safety, says Michael Dorn, executive director of the campus-safety advocacy group Safe Havens International in Macon, Georgia. "I see a lot of people who are very accomplished but also very reckless," he says. "You may be a great researcher, but it doesn't make sense to disregard danger."

Scientists in every discipline and every setting should apply their analytical skills to the possible hazards around them, Dorn says. "The brain is a very powerful survival mechanism," he says. As a start, he recommends paying close attention to other people, noting behaviours or activities that seem out of place. "Scientists are very good at recognizing 
patterns," he says. "If something seems odd, they should take that seriously."

And if junior researchers feel unsafe about some aspect of the job - whether it is late nights at the lab or field work in a dangerous part of the world - they should consult their superiors. "It's very prudent to ask questions and raise concerns if you have them," he says. Once questions are asked, the principal investigator (PI) may suggest new safeguards, such as eliminating night-time experiments or that people work in pairs. If nothing else, Dorn says, questions help to keep safety in the conversation.

Whether they are working at a far-flung site or close to home, PIs should have clear and explicit rules for staying safe, and junior researchers need to make sure that they understand the reason for every mandate.

\section{SAFETY FIRST}

Danti has a set of safety rules for his digs: nobody works alone, nobody drives at night and junior trainees never drive. He is not concerned about the vehicle; rather, he worries that the person driving could end up being be stoned to death if they accidentally hit a villager and are not familiar with local customs and protocols for behaviour. Once lab members understand the rationale, it pretty much eliminates the likelihood of a joy ride. He also has several strategies in place for leaving a country in a hurry, and tries to makes sure that whenever it is possible, he has an Internet connection to keep track of the swirling politics and conflicts in any region.

Yet even staying connected can have a downside. Having online access, he points out, means that some team members may be too distracted by social media to focus on the potential hazards around them. "It feels like the set of a reality show," he says. "They aren't paying attention to personal safety."

Dorn, whose travels have taken him to troubled regions all over the world, says that all researchers should go online to check for official travel notices - such as the foreign travel advice at go.nature.

com/zioaff or alerts and warnings from the US Department of State - before heading to potentially hazardous areas.

Travel to specific countries is rarely banned outright, but there are often many things to keep in mind. For example, the state department currently advises drivers in Mexico to reduce the risk of carjacking by driving between cities only during daylight hours and using toll roads whenever possible.

A camp that is too remote for Wi-Fi or mobile-phone reception should at least have a satellite phone, Dorn says. Even then, however, the necessary evacuation might not be possible if the PI doesn't have medical rescue insurance. Dorn says that insurance policies

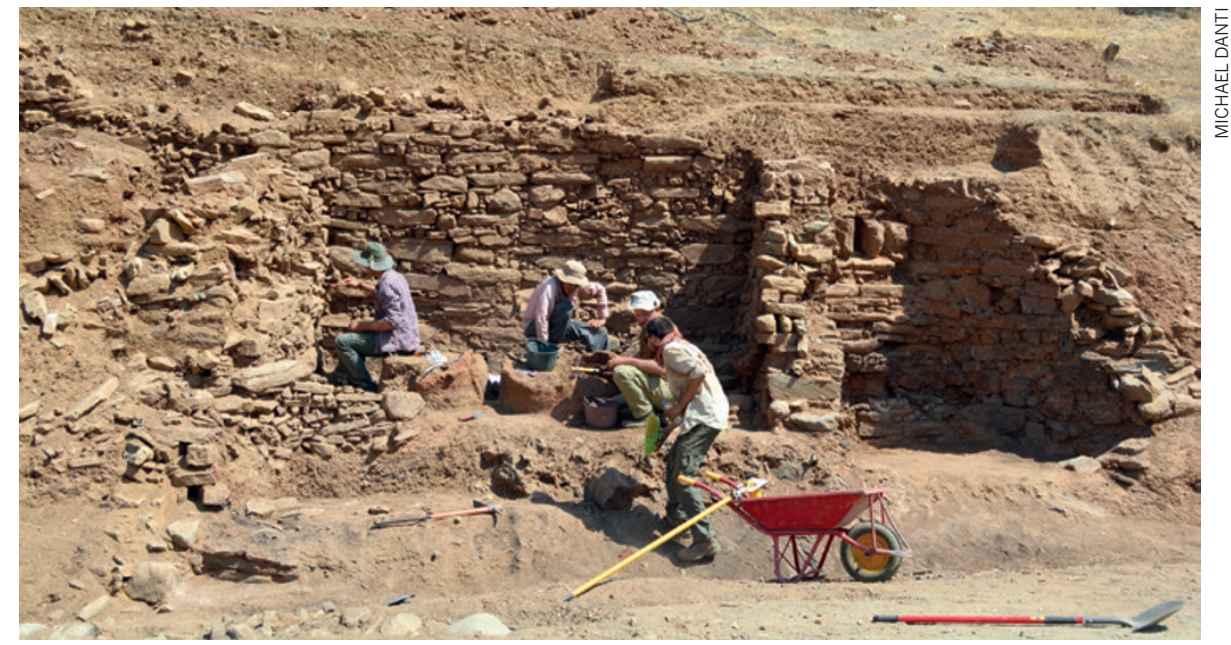

Michael Danti's team at the tomb complex of Gund-i Topzawa (400 BC) in northeastern Iraqi Kurdistan.

are worth double-checking: some cover rescue landings and take-offs only if they are from paved airstrips, which are not always an option out in the field. "You have to ask, "If something happens at this particular site, will somebody come to get me?"”

Some PIs need to rethink the casual, anything-goes culture that seems commonplace at field sites, says Katie Hinde, a human evolutionary biologist at Harvard University in Cambridge, Massachusetts. "It's like an adventure, a vacation or a camping trip," she says. "There's a relaxation of professionalism." She says that in conversations with other scientists and during interviews with people participating in a study she co-authored called Survey of Academic Field Experiences (SAFE) report (K. B. H. Clancy et al. PLoS ONE 9, e102172; 2014), she has heard many variations on the same story: researchers who were generally respectful in the lab seemed transformed in the field, leading to inappropriate behaviour and unwanted physical contact. And in fact, one-fifth of the 516 women and 150 men who participated in the study said that they had been sexually assaulted during a field trip. Several said that they had experienced multiple assaults.

Protecting scientists from one another can be a tricky and delicate task, says Hinde. As a first step, she says, PIs should remind all team members (and themselves) that the university's code-of-conduct rules apply to the field as well as the lab. Yet, many seem to be silent on such issues, especially in the field. Fewer than twofifths of the people who responded to the SAFE survey recalled ever having been briefed about rules of conduct. "PIs shouldn't feel obligated to follow those rules just because it's the law," she says. "They should do it because they care about their colleagues."

Hinde believes that safety considerations regarding colleagues as well as outsiders should be part of any grant application for field work. It would be an official acknowledgement of a problem that should not be ignored. "This hadn't been on people's radars because people didn't talk about it," she says. "Now a lot of people are working very hard to make their field sites safe."

\section{USE INITIATIVE}

Dorn, a former police lieutenant at Mercer University in Macon, Georgia, says that some researchers seem to court trouble by working alone and keeping late hours. He says that a police officer on his team once pulled a gun on Mercer's president after mistaking him for an intruder in the middle of the night. After that, the president vowed to let security know when he would be working late. Dorn also recommends that researchers who need to work late at night check with campus security for advice and support, or for a ride, if it does not seem safe to walk into a car park or across a vast, dark campus. "I would rather drive someone around 500 times than investigate a rape," he says.

Dorn says that one strategy researchers can use to help improve their safety is visualization. The idea is to calmly visualize every potentially dangerous situations and decide ahead of time how to react. That way, "you're preloading your brain with information", he says. Law-enforcement officers, soldiers and athletes have been using the technique for decades to map out strategies for various what-if scenarios. With a plan in place for each one, he says, they can proceed with confidence and alacrity.

Dorn and his colleagues discuss visualization and other safety strategies at the website safehavensinternational.org/staying-alive.

The potential for danger has not stopped Danti from pursuing his passion. "I love Syria, Iran and Iraq," he says. "I love the people and the culture."

Even more than that, however, he loves bringing his team home safely. And once he is back in his office, he can start thinking about everything that can go wrong next time.

Chris Woolston is a freelance writer in Billings, Montana. 